\title{
37
}

\section{Performance Measurement - An Important Tool in Change Process}

\section{T. Laakso' and J. Karjalainen ${ }^{b}$}

- Senior Researcher, Institute of Industrial Automation, Helsinki University of Technology, Otakaari 4 A, 02150 Espoo Finland.

${ }^{b}$ Senior Researcher, Department of Industrial Management, Helsinki University of Technology, Otakaari 4 A, 02150 Espoo Finland.

Key words: performance indicators, performance measurement, management of change, performance management

\begin{abstract}
The increased interest in performance measurement (PM) has caused the Federation of Finnish Metal and Engineering Industries to include PM as one of the subject areas of its CIM development program. The Helsinki University of Technology took part in this program by means of a questionnaire study concerning the present state, a number of case studies in various companies considered best in class in performance measurement, and building PM systems for Finnish companies. The questionnaire revealed that present PM systems seem to overemphasize financial measures, whereas measures that support modern manufacturing initiatives' of importance for change management are missed. The case studies helped to establish procedure for implementing PM. One of the most important lessons has been that the human aspects of PM must be emphasized in order to achieve successful result.
\end{abstract}

\section{Motivation}

At the same time when enterprises are applying new manufacturing initiatives such as JIT, TQM, Lean, etc. there is an urgent need for new management tools to implement these initiatives. The capability of a company to implement new strategies distinguishes a high-performing company from average companies. A properly defined and implemented performance measurement system is a tool that facilitates the implementation of the strategy of a company. Besides providing feedback on business and production process performance to operators and management, performance measurement facilitates learning and drives continuous improvement.

As the Finnish industry has become more and more aware of the importance of PM, the Helsinki University of Technology (HUT) has directed some research effort on developing PM systems. During the past two years HUT has been carrying out a number of studies concerning PM. One of the studies explored the use of present and planned PM among Finnish manufacturing enterprises. Studies were also carried out in companies that had been using PM for some time. In addition to this we assisted some companies to design and to implement partial PM systems. The PM research work has been carried out in co-operation with the Federation of Finnish Metal and Engineering Industries (FIMET) and a number of industrial enterprises as a part of the CIM development program for Finnish metal and engineering industry (SIMSON). 


\section{The Questionnaire Study}

The aim of the study was to clarify the current situation of PM in the Finnish industry. The study seeks to establish the target areas of measurement and needs for further development of measurement systems. Furthermore examples of actual measures used in companies have been gathered and the importance of the measures have been explored.

We have used the Performance Measurement Questionnaire (PMQ) developed by Prof. Nanni et. al. at Boston University [1]. The questionnaire study was carried out among members of FIMET. FIMET consists of companies representing the Finnish metal and electrical industry. 1350 questionnaires were sent to 400 companies. 123 responses were received from 82 companies.

Originally the PMQ was designed to be applied internally in an organization. The objective was to provide a means by which an organization can articulate its improvement needs with regard to performance measures. It determines the extent to which the existing PM system of the organization supports necessary improvements and establishes guidelines for designing the measurement system. As mentioned we have used the PMQ method to analyze the status of PM systems use among several businesses and not within an individual company.

The PMQ is composed of four major parts. The first part consists of some general data of the individual respondents and the companies they are working in. The respondent has been asked about his or her position, organizational level, and about the functional area in which he or she works. Also the name of the company, turnover and total number of employees in the company has been asked for.

The second part of the PMQ focuses on competitive priorities and the current PM systems of the companies. In this section 27 improvement areas have been listed. Examples of listed improvement areas are quality, labor efficiency, volume flexibility, information systems, etc. The form of the questionnaire has been presented in figure 1 .

\begin{tabular}{|c|c|c|c|}
\hline Long-Aun Importance & Improvements Areas & Ethect of Current & Not \\
\hline \multirow{2}{*}{ of Improvomont } & & \multirow{2}{*}{$\begin{array}{l}\text { PAl eysiom on } \\
\text { Improvoment }\end{array}$} & usod \\
\hline & & & \\
\hline Nono $>>>>$ & & Inhlblt $\gg \gg>$ Support & \\
\hline 1234567 & QUALITY & \begin{tabular}{|llllllll}
1 & 2 & 3 & 4 & 5 & 6 & 7
\end{tabular} & 0 \\
\hline 123345667 & LABOR EFFICIENCY & 1223345567 & 0 \\
\hline 1223345667 & VOLUME FLEXIBILITY & 1234567 & 0 \\
\hline $\begin{array}{lllllll}1 & 2 & 3 & 4 & 5 & 6 & 7\end{array}$ & INFORMATION SYSTEMS & $\begin{array}{llllllll}1 & 2 & 3 & 4 & 5 & 6 & 7\end{array}$ & 0 \\
\hline
\end{tabular}

Figure 1. The form of the PMQ.

On the left-hand scale, respondents have been asked to evaluate the importance of the improvement area for the long-term competitiveness of the company. The number 1 indicates that maintaining the present level of the area is adequate to meet future requirements, while the number 7 indicates that major improvements are required in that area in the future. On the righthand scale, respondents evaluate the influence of the PM system of the company in supporting or inhibiting improvements in that area. 
The third part of the PMQ is being constructed similarly than part two, but the focus is on performance factors that could also be called performance measures. In the PMQ 38 performance factors have been listed. Examples of the factors are inventory turnover, cost of quality, manufacturing lead time, vendor quality, etc.

On the left hand scale, respondents give their opinion as to the importance of achieving excellence in this factor for the long-run health of the company. The scale is from none (1) to great (7). The right-hand scale measures the extent to which they believe the PM system of the company emphasizes that factor.

The fourth part of the PMQ clarifies individual and company specific performance measures. Respondents are asked to record measures that are used in their companies. Measures have been evaluated as in part three of the PMQ.

\section{Results of The Performance Measurement Questionnaire Study}

Alignment analysis provides a general overview of the consistency between strategy, actions, and measures. Analysis has been made by averaging both left-side and right-side responses as to improvement areas and measurement factors. After the responses have been sorted in descending order, the top and bottom quartile are listed. In table 1 are the results of the alignment analysis of the improvement areas and in table 2 are the results of the analysis of performance factors.

Table 1. Alignment analysis of the improvement areas of all respondents.

\begin{tabular}{|l|l|c|l|}
\hline \multicolumn{2}{|l|}{ Long-run Importance } & \multicolumn{3}{|c|}{ Effect of the Current PM system } \\
\hline 1 & Customer satisfaction & 1 & Direct cost reduction \\
\hline 2 & Manufacturing throughput time & 2 & Overhead cost reduction \\
\hline 3 & Integration with customers & 3 & Inventory management \\
\hline 4 & Quality & 4 & Capital use \\
\hline 5 & Capital use & 5 & Manufacturing throughput time \\
\hline
\end{tabular}

\begin{tabular}{|l|l|c|l|}
\hline 23 & Machine efficiency & 23 & New product introduction \\
\hline 24 & Information systems & 24 & Information systems \\
\hline 25 & Product technology & 25 & Product mix flexibility \\
\hline 26 & Product mix flexibility & 26 & Product technology \\
\hline 27 & Environmental control & 27 & Environmental control \\
\hline
\end{tabular}


Table 2. Alignment analysis of the performance factors of all respondents.

\begin{tabular}{|l|l|l|l|}
\hline \multicolumn{2}{|c|}{ Long-run Importance } & 1 & Emphasis of the PM system \\
\hline 1 & On-time delivery & 2 & Deviation from budgets \\
\hline 2 & Sales margins & 3 & Return on investment \\
\hline 3 & Cost reduction & 4 & Inventory turnover \\
\hline 4 & Return on investment & 5 & Cost reduction \\
\hline 5 & Customer survey & 6 & On-time delivery \\
\hline 6 & Manufacturing lead times &
\end{tabular}

\begin{tabular}{|l|l|c|l|}
\hline 33 & Process R\&D costs & 33 & Indirect labor productivity \\
\hline 34 & Number of engineering changes & 34 & Number of material part numbers \\
\hline 35 & Number of suppliers & 35 & Productivity of middle management \\
\hline 36 & Education and training budgets & 36 & Environmental monitoring \\
\hline 37 & Number of material part numbers & 37 & Productivity of supervisors \\
\hline 38 & Environmental monitoring & 38 & Productivity of specialist \\
\hline
\end{tabular}

When looking at the above results some interesting facts can be seen. "Integration with customers" have been considered one of the most important areas of improvement in the future, but when one looks at the top performance factors customer surveys are not mentioned at all. Respondents were satisfied with the present level of cooperation with suppliers. However, quality and throughput time of the manufacturing have been seen as an area of improvements on which supplier quality and on-time delivery have a major influence.

The greatest differences between left-side and right-side scores will be the main ingredients of what is called the gap analysis. The bigger the gap is the more the performance factor calls for increased support by the measurement system. If the sign of the difference is negative then the performance factor is called a false alarm. The tables 3 and 4 summarizes the biggest gaps and false alarms that have been found.

Table 3. The gaps and the false alarms of the improvement areas.

\begin{tabular}{|l|l|c|l|}
\hline \multicolumn{2}{|c|}{ Gaps } & \multicolumn{3}{c|}{ False alarms } \\
\hline 1 & Customer satisfaction & 1 & Capital use \\
\hline 2 & Flexibility of capacity & 2 & Environmental control \\
\hline 3 & Integration whit customers & 3 & Overhead cost reduction \\
\hline 4 & Marketing & 4 & Inventory management \\
\hline 5 & Multiskilled workers & 5 & Direct cost reduction \\
\hline
\end{tabular}

Table 4. The gaps and the false alarms of the performance factors.

\begin{tabular}{|l|l|l|l|}
\hline \multicolumn{2}{|c|}{ Gaps } & \multicolumn{2}{c|}{ False alarms } \\
\hline 1 & Productivity of specialists & 1 & Deviation from budgets \\
\hline 2 & Productivity of middle management & 2 & Inventory turnover \\
\hline 3 & Productivity of top management & 3 & Education and training budgets \\
\hline 4 & Productivity of supervisors & 4 & Sales margins \\
\hline 5 & Productivity of indirect labor & 5 & Return on investment \\
\hline 6 & Supplier performance & 6 & Production goals \\
\hline
\end{tabular}


The individual measures that the respondents have listed, can be classified into financial and nonfinancial. The ratio between these is $50 \% / 50 \%$. Because the measures listed varied so much, we decided to classify them into nine categories. The categories of the measures are shown in figure 2 .

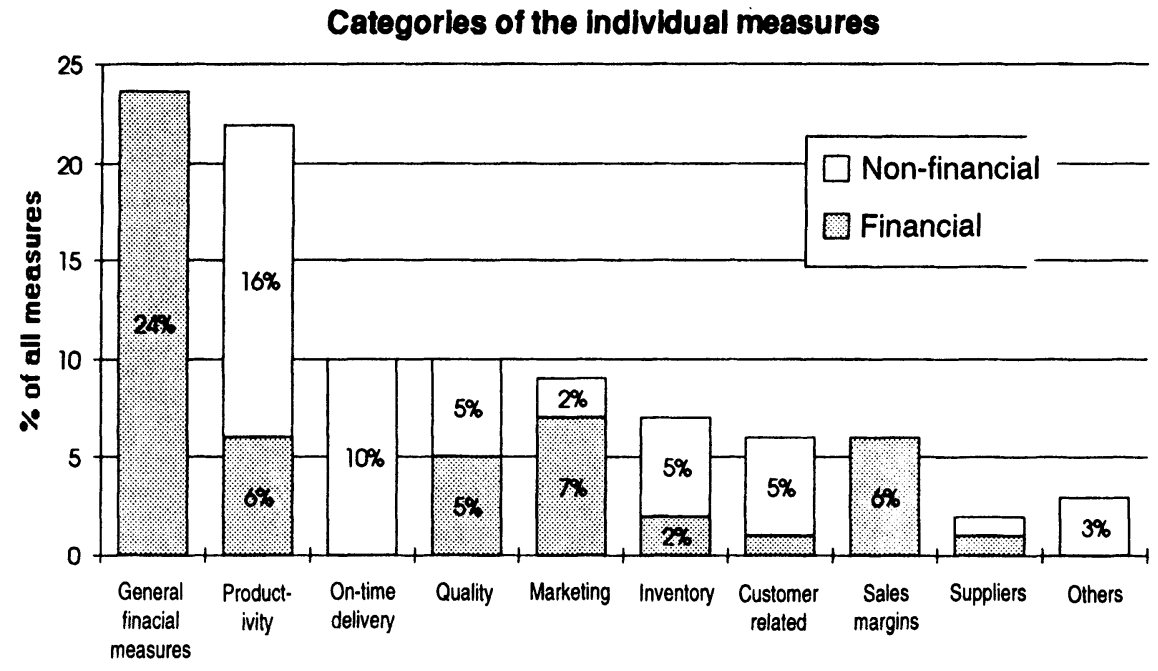

Figure 2. The distribution of the performance measures used in the companies.

In the gap analysis of the individual measurements, it has been pointed out that the most difficult categories of measures are related to suppliers and customer, and quality. It did not pass unnoticed that most of the measurements are focusing on results instead of causes. Emphasis is put on ROI, inventory turnover, variances, etc. instead of delivery precision, response times, machine failures, etc.

PMQ is primarily a diagnostic tool. There is also a need to extend the model to encompass such factors as management style, the structure of the organization and the procedures for strategy deployment.

\section{Case Studies}

In the best practice studies four Japanese, four American, one French, one German, one Swedish, and two Finnish companies have been included. In addition to carrying out the case studies more than a dozen small scale performance measurement systems has been installed at a number of companies. 
From the cases we have learned that PM is a very versatile tool for management. Among the enterprises involved in our studies the following application types have been found:

1. Problem solving and problem spotting

2. Process control

3. Improvement of all important operational aspects

4. Measurement as a basis for bonus payment

5. Introduction of new management paradigms

6. Emphasis on human factors

In the Japanese companies studied by us, the abbreviation Q.C.D.S. was most often quoted as the essence of PM. Q.C.D.S stand for Quality control, Cost management, Delivery management, and Safety control in that order of importance. Q.C.D.S is the key of strategy deployment of the company and it is also the base of self management. All case companies had improvement (Kaizen) programs that contribute to all these four areas. In figure 3 the structure of the PDCA (Plan Do Check Act) management system is shown in one of the Japanese case companies.

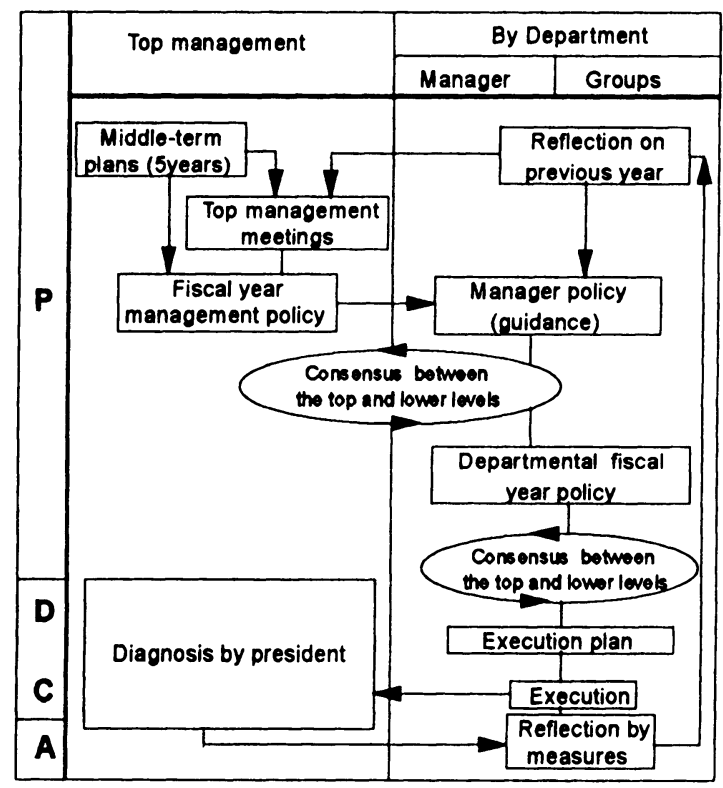

Figure 3. Management system of the NEC Shizuoka.

Japanese companies are forerunners in taking advantage of visual management. Graphs of the measures can be seen along the hallways and around the work cells. Photographs are also used widely to show working procedures and standard levels. The group or the team, whose 
performance is measured, is responsible for maintaining these measurements. It is one way of getting the operator level involved and empowered.

In the Swedish case a new human dimension has been added to the traditional cost and quality improvement dimensions. Human dimension measurements have been extended to encompass such features as skill, motivation, participation, and empowerement. The PM system of this case company was a byproduct of a large improvement project. The primary aim of the project was to reduce the number of staff personnel and management, and to distribute the responsibility to the heads of manufacturing cells and to self managed teams, and to simplify the lay-out. However, to work effectively towards a common goal the new organization needed a new PM system. This new PM system has three levels described by different colors: red, yellow, and green. The red measures are indicating performance at the factory level. The yellow measures depict efficiency at departmental level. Performances at cell level is shown by green measures. Depending on the organizational level the reporting interval is monthly, or weekly, or daily. Each level determines and maintains the measures indicating its performance. The performance measures must cover all three dimensions: costs, quality/delivery, and human factors. More and more challenging targets are constantly attached to the measures because one of the aims of the operation is continuous improvement.

In the French case the PM system has been developed as a part of a target setting and problem solving mechanism, aiming at pushing process improvement decisions down the hierarchy line, in order to utilize all available knowledge. By means of the PM system management should learn how to share responsibilities and to understand cause/effect relationship of the operations.

According to the management philosophy of the French case company continuous improvement and elimination of waste are supported through:

1. Action plans that are formally managed and which recognize the crossfunctional interdependencies of the operations.

2. Measurements that are formally defined are shared at factory level.

3. Rolling forecast that is prepared monthly and which commits employees to the operational targets.

4. Regular management meetings that are focused to set and re-set new targets and in which action plans are initiated and reviewed.

A large number of indicators (measurements) is used in the company. Totally there are around 300 indicators of which $90 \%$ are non-financial and $10 \%$ are financial. Most of the indicators are reviewed in an action group that concentrates on problem solving activity. Problem spotting concerns only few key indicators. The new PM supported management procedure of the company is described in figure 4. 


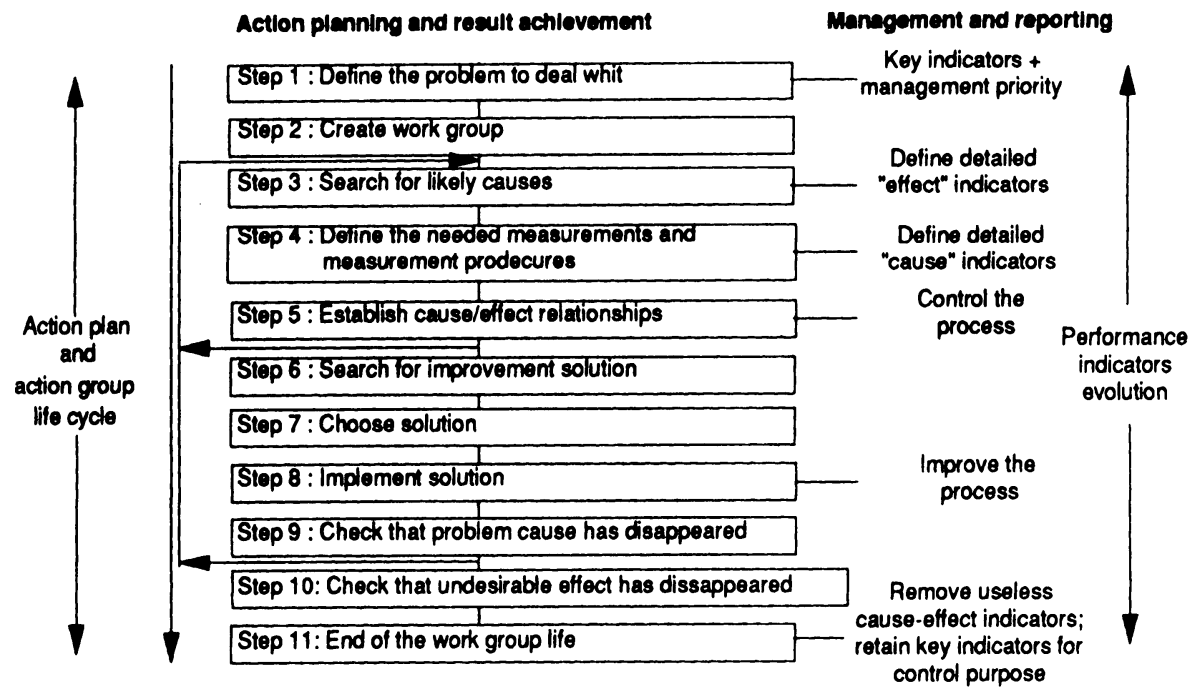

Figure 4 . The management procedure of the French case company.

In the Finnish case the PM was a byproduct of establishing a new personnel appraisal system forming the basis of individual bonus payment. The new system covers both staff and manufacturing floor personnel. The part of the PM that is applied to staff personnel, is of special interest. It is an area of PM that often is referred to as the most difficult to put into practice. The four bonus connected areas of employee performance are profitability, quality, delivery, and development targets.

The projects which aimed at installing small scale PM systems in a number of industrial companies covered the following areas: internal and external delivery precision, supplier quality, logistics, productivity, throughput, quality, purchasing, and information systems. The experience gained from these projects has been mainly positive. We learned that the first step of the PM system project need not be a gigantic one. Small steps can lead to substantial improvements without using a lot of manpower, money and time.

What have we learned from our studies? First of all we have identified three main company categories. In category one companies performance measurement is abundantly and widely used as a universal tool. PM systems are created by a bottom-up-design and top-down-checking. Each organizational level has a number of individual measures designed by the level personnel itself. In category two companies PM is successfully used for specific purposes only. In category three companies the performance is measured mainly for routine reasons, such as accounting, reporting or controlling. In such companies the idea of PM is easy to sell to top management but the lower down in the organization you go, the more resistance you will encounter. In this category top management often views PM as an additional tool for control instead of self management. 


\section{Typical difficulties encountered}

Although most people accept the general ideas of a good performance measurement system there are a number of dangers that can harm the well-started development project. The following list is collected during the various stages of our PM-project.

- The role of the measures in self management, empowerment and learming is not fully understood. Performance measurement is only considered to be a management control tool.

- Measures are dictated, although in a civilized manner, top-down. People are not allowed to include their own measures or measures that have an understandable meaning for their daily work.

- The visualization of the measures is ignored. Measures remain numeric, and they do not motivate people for continuous improvement.

- Too much effort is used to describe the present situation, and the project team is wom out before the creative work begins.

- Measures reflect too much the organization chart. Thus, they isolate different functions instead of uniting them into business processes.

- Measures are chosen subjectively, and they are not explicitly linked to the strategies and goals of the business.

- The participation of those who will be measured is ignored. An inpatient, but talented individual can dominate the process. The measures become his measures, and the true owners of the measures get frustrated.

- Measures do not become a part of the daily activities. After the first enthusiastic implementation period, measures remain unused because those who were not involved in the development process do not understand the meaning of measures.

To avoid these usual setbacks of performance measurement, a normative process of implementing performance measures is described below [4].

\section{How to implement performance measures}

Our general framework of performance measurement (fig. 5) includes strategies, business process to be measured, set of measures, situational characteristics and the continuous implementation process. There must be a link between the overall objectives and the objectives of any single unit. Performance measures are tools to establish this link and synchronize people's actions.

Examples taken from other companies and checklists from the literature are commonly used practical aids during the implementation phase. All the applicable measures should be tied to the conceptual framework of the company. So, the battery of metrics is a structured catalog of reasonable measures, not just an ad-hoc list. Every measure is linked to a performance factor or an improvement area, such as quality, customer satisfaction, human resources or waste. Thus, any chosen measure is a part of a larger entity.

Situational characteristics, such as present problems, former experience or work-force attitudes, are strongly dependent on the business unit that requires new or revised performance measures. Connection to overall objectives is important in order to achieve correctly directed actions. However, if the measures ignore the local realities, no true improvement is activated. 


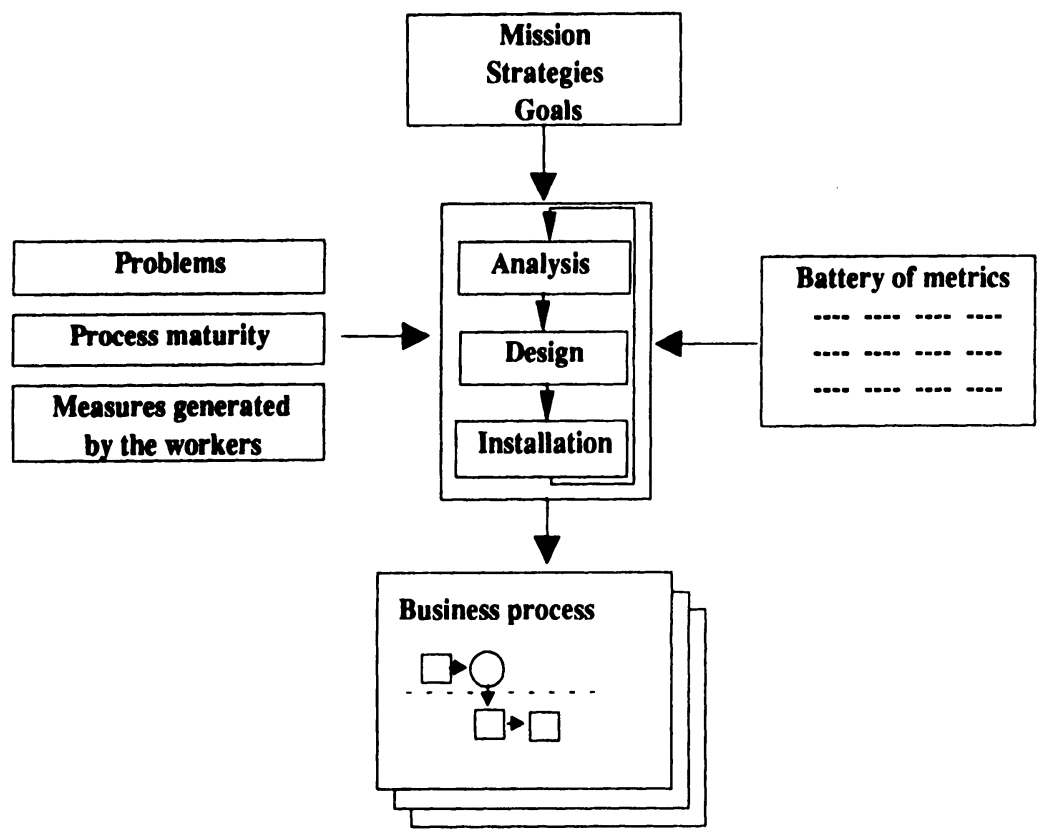

Figure 5. The general framework of establishing performance measurement

The implementation process includes the following main phases: analysis, design and installation. Especially in a change process, a major PM system implementation project can be identified as a part of the improvement project. If the old measurement system requires radical changes, it is easy to see the project approach, too. However, one should understand that the once implemented measures need to be continuously revised, because companies do not operate in a static environment.

Figure 6 summarizes the necessary steps included in the three main phases. The order of the steps is not rigid, and in some cases all steps may not be seen so clearly. Some steps are discussed more closely in the following paragraphs. It is important to notice, that the questions that need to be solved become more detailed when moving from analysis to installation. In a practical implementation process, there is always some iteration.

The analysis phase can be relatively long, starting right after the previous installation and continuing until the need for redesign is clarified. Naturally, some modifications to the installation may take place during the analysis period. The most important results that must be achieved before the design phase can begin are following: the reason for measuring and the activation of the right people. 


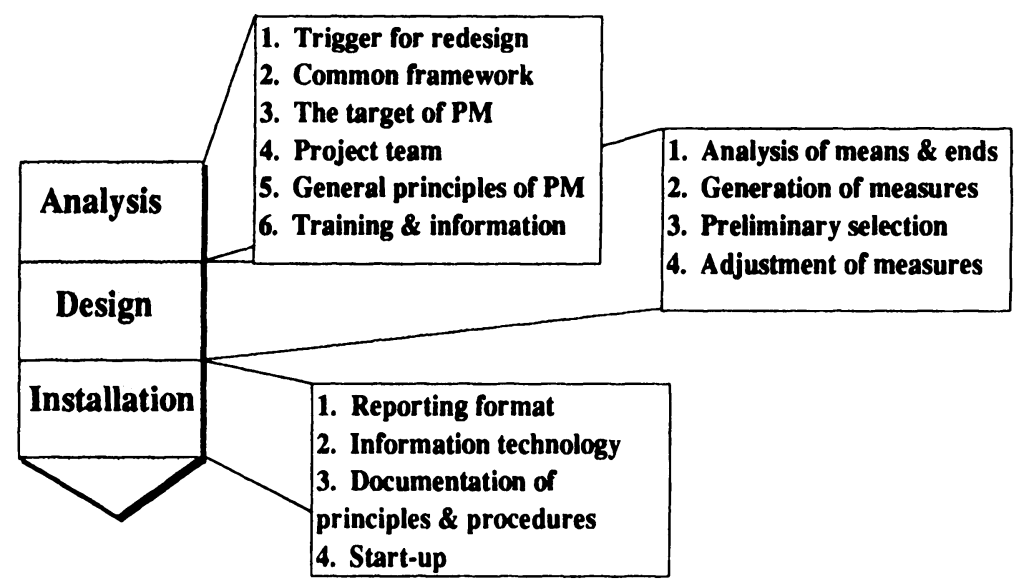

Figure 6. The steps of implementation

The reason for measuring identifies the target group of the measures (business unit, process, design team) and the link from measures to business objectives. In a change process, the need to reshape the way people think and act is essential. So, the concepts and frameworks of communication should not be ignored. The modem initiatives may be clear for the management élite, but the focal point is to get everybody to understand what, for example, JT or Lean means in their own work. Therefore, process mapping, team work techniques (e.g. storyboards) and questionnaires (e.g. the Performance Measurement Questionnaire) are suggested tools for this step.

The team that makes the design and installation must have a right mixture of people who set overall business objectives (top management), those who are responsible for achieving the objectives (middle management, supervisors and operators) and those who are familiar with the technical aspects of measurement (IT experts, consultants). The role of the supervisors and operators is the most important, and the participation of these people must be supported by training and information. The role of top management is strongest in the early stages of the implementation project; whereas IT experts are mostly needed in the installation phase.

The design phase includes the analysis of means and ends, selection of measures, and refinement of selected measures. There are some widely accepted objectives, like good quality or short throughput time. The basic measures for these objectives can be easily chosen from a list of measures. Even for benchmarking purposes, it may be relatively easy to find a measure that is meaningful in different organizations. However, each organization must examine the cause and effect relations behind any general metric. Fishbone analysis is a simple but effective tool for this. The analysis of means reveals new factors to measure, and these measures are usually closer to people's daily operations than the original end-measure. Another important result of the fishbone analysis may be that some unfavorable means are identified.

The adjustment of measures includes analysis of possible conflicts of interests. Performance measures must be close to the people, and so, each work group must have independence in 
choosing the measures. There is a danger, however, that measures drive actions that move problems from one group to another, not actions that terminate problems.

Another aspect of refinement is more psychological by nature. Same factors can be measured using slightly different measures, but one of the possible ways may be more inspiring and motivating. Positive measures are usually more effective than negative ones; so, one should measure successes instead of failures.

In addition to various aspects related to information technology, the installation phase includes design of reporting format and documentation of measurement principles and procedures. The best practices companies seem to have paid great attention to the visualization of measures. Using different kinds of graphs, critical aspects can be high-lighted, unimportant details can be faded, and various factors can be compared or combined.

The documentation of measurement principles and procedures is necessary to make sure that the ideas collected earlier are not forgotten. It must also be assured that those who were not directly involved in the process will understand the measures correctly. Important points in the document, besides the issues considered earlier, are the following: the procedure of setting and updating target values and control limits, suggested actions if control limits are broken, responsibilities and procedures of gathering and transforming data, and frequency and delivery of measures.

\section{Future research activities}

We have learned that PM is a universal technique that can be applied to practically speaking all regular as well as change management situations of a company. This is shown in figure 7.

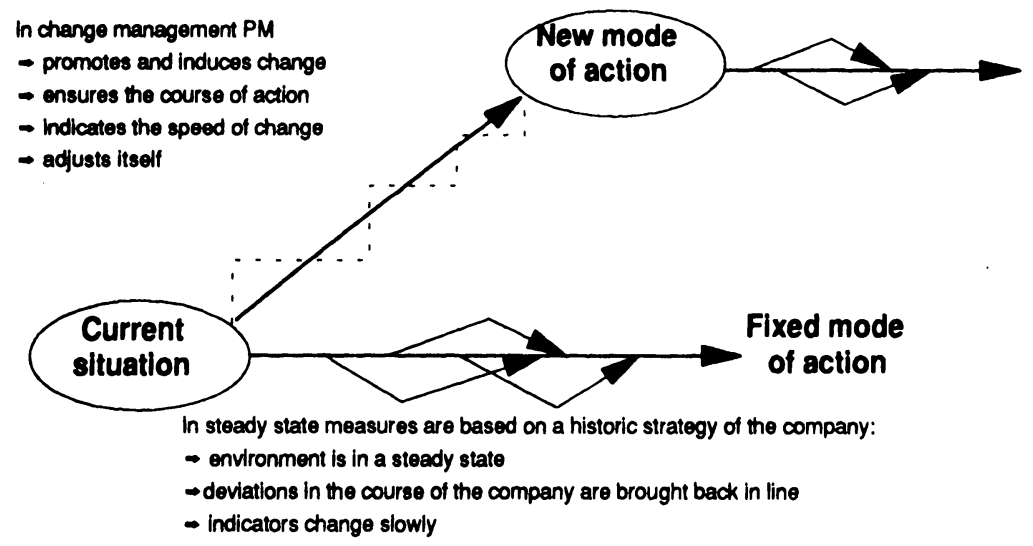

Figure 7. The different areas where performance measurement can be applied 
The path we are following in our further research is to clarify the problems of managing change. Managerial attention must shift from maintaining current operations to managing strategic evolution. The capability to implement rapidly and successfully new manufacturing practices is the key issue when we try to maintain the competitiveness of the enterprise. In order to manage the evolution of the enterprise many new tools and methods must be developed.

The result of the project will be a tool kit that will guide companies through the phases of change identifying which areas/processes to measure, developing suitable measurement criteria for the chosen processes, analyzing results, and making comparisons.

\section{References}

1. Nanni,A. \& Vollman, T. \& Dixon, J., The New Performance Challenge; Measuring Operations For World-Class Competition. Homewood, Illinois 1990, Richard D. Irwin Inc. 199 pages.

2. Laakso, T., Performance Measurement: a Tool for Management, Licentiate Thesis, Computers in Industrial Production, Helsinki Univesity of Technology, Otaniemi, 1993 127 pages. (in Finnish)

3. Andersin, H. \& Laakso, T., Performance Measurement as a tool for management and selfmanagement - cases and conclusions. 12th ICPR seminar, August 16-20, 1993, Lappeenranta.

4. Andersin, H., Karjalainen, J. \& Laakso, T., Performance Measurement as a Driver of Actions. Publication of FIMET 1994. 121 pages (in Finnish). 